\title{
Reactivation from latency displays HIV particle budding at plasma membrane, accompanying CD44 upregulation and recruitment Mari Suyama1, Eriko Daikoku² ${ }^{2}$ Toshiyuki Goto ${ }^{3}$, Kouichi Sano ${ }^{2}$ and Yuko Morikawa*1
}

Address: ${ }^{1}$ Kitasato University, Shirokane 5-9-1, Minato-ku, Tokyo 108-8641, Japan, ${ }^{2}$ Osaka Medical College, Daigaku-cho 2-7, Takatsuki, Osaka 569-8686, Japan and ${ }^{3}$ School of Health Science, Faculty of Medicine, Kyoto University, Kawaraha-cho 53, Shogoin, Sakyo-ku, Kyoto 606-8507, Japan

Email: Mari Suyama - maris@lisci.kitasato-u.ac.jp; Eriko Daikoku - edaikoku@art.osaka-med.ac.jp; Toshiyuki Goto - tgoto@hs.med.kyotou.ac.jp; Kouichi Sano - ksano@art.osaka-med.ac.jp; Yuko Morikawa* - morikawa@lisci.kitasato-u.ac.jp

* Corresponding author

Published: 13 July 2009

Retrovirology 2009, 6:63 doi:10.1/86/1742-4690-6-63

This article is available from: http://www.retrovirology.com/content/6/1/63

(C) 2009 Suyama et al; licensee BioMed Central Ltd.

This is an Open Access article distributed under the terms of the Creative Commons Attribution License (http://creativecommons.org/licenses/by/2.0), which permits unrestricted use, distribution, and reproduction in any medium, provided the original work is properly cited.

\begin{abstract}
Background: It has been accepted that HIV buds from the cell surface in T lymphocytes, whereas in macrophages it buds into intracellular endosomes. Recent studies, on the other hand, suggest that HIV preferentially buds from the cell surface even in monocytic cells. However, most studies are based on observations in acutely infected cells and little is known about HIV budding concomitant with reactivation from latency. Such studies would provide a better understanding of a reservoir for HIV.
\end{abstract}

Results: We observed HIV budding in latently infected T lymphocytic and monocytic cell lines following TNF- $\alpha$ stimulation and examined the upregulation of host factors that may be involved in particle production. Electron microscopy analysis revealed that reactivation of latently infected JI.I cells (latently infected Jurkat cells with HIV-I) and UI cells (latently infected U937 cells with HIV-I) displayed HIV particle budding predominantly at the plasma membrane, a morphology that is similar to particle budding in acutely infected Jurkat and U937 cells. When mRNA expression levels were quantified by QRT-PCR, we found that particle production from reactivated JI.I and UI cells was accompanied by CD44 upregulation. This upregulation was similarly observed when Jurkat and $U 937$ cells were acutely infected with HIV-I but not when just stimulated with TNF- $\alpha$, suggesting that CD44 upregulation was linked with HIV production but not with cell stimulation. The molecules in endocytic pathways such as CD63 and HRS were also upregulated when UI cells were reactivated and U937 cells were acutely infected with HIV-I. Confocal microscopy revealed that these upregulated host molecules were recruited to and accumulated at the sites where mature particles were formed at the plasma membrane.

Conclusion: Our study indicates that HIV particles are budded at the plasma membrane upon reactivation from latency, a morphology that is similar to particle budding in acute infection. Our data also suggest that HIV expression may lead to the upregulation of certain host cell molecules that are recruited to sites of particle assembly, possibly coordinating particle production. 


\section{Findings}

It has been thought that HIV particles assemble and bud at the plasma membrane (PM) in T lymphocytes and HeLa cells, but at the endosomes in macrophages, suggesting that such endosomal targeting may be essential for HIV budding in macrophages [1-6]. However, recent studies using the inhibitors of the endocytic pathway and membrane-impermeant dyes have revealed that the PM is the primary site for HIV assembly and particle budding even in macrophages and that particles accumulate at the endosomes through endocytosis [7-9]. Nevertheless, these studies are based on observations in acutely infected cells and little is known about HIV budding concomitant with reactivation from latency. Latently infected resting $\mathrm{T}$ cells are known to serve as a stable reservoir for HIV during anti-retroviral therapy and to produce infectious particles upon cell reactivation. Studies on HIV production from latently infected cells upon reactivation are necessary for a better understanding of HIV pathogenesis, although some studies have indicated intracellular accumulation of particles in chronically or latently infected cells $[10,11]$. Here, we employed J1.1 cells that were Jurkat T lymphocytic cells latently infected with HIV-1, and U1 cells that were U937 monocytic cells latently infected with HIV-1, and observed HIV particle budding following reactivation.

We initially tested the dose of TNF- $\alpha$, and temporally monitored cell growth and HIV particle production after stimulation (Fig. 1A). J1.1 cells proliferated equally regardless of the dose of TNF- $\alpha$, and the particle production levels increased to $50 \mathrm{ng} / \mathrm{ml} \mathrm{TNF-} \alpha$. In contrast, proliferation of U1 cells was inhibited in a dose-dependent manner, and the highest level of particle production was observed at $50 \mathrm{ng} / \mathrm{ml}$. We thus used $50 \mathrm{ng} / \mathrm{ml} \mathrm{TNF-} \alpha$ for further experiments. To avoid nonspecific stimulation by changing the medium, we added TNF- $\alpha$ directly to the culture medium, and this led to the higher dose of TNF- $\alpha$ required in our study than in other reports $[12,13]$.

Electron microscopy was carried out to examine where particle budding occurred in J1.1 and U1 cells upon reactivation (Fig. 1B). Little or no particles were produced in either cell line before TNF- $\alpha$ stimulation (Fig. 1B, most left panels), consistent with previous reports [11-14]. Upon stimulation, nascent budding particles were visible on the surface of nearly all J1.1 cells, similar to the case with U1 cells (Fig. 1B, arrowheads). Unexpectedly, particles in intracellular vesicles were rarely seen in both J1.1 and $\mathrm{U} 1$ cells (Fig. 1B, arrow). The findings were confirmed by immunoelectric microscopy using anti-HIV-1 p17MA antibody (Fig. 1B, most right panels). Next, their parental cell lines, Jurkat and U937 cells, were infected with HIV-1, and particle production in acute infection were examined by electron microscopy. Particle budding was observed predominantly at the PM of both Jurkat and U937 cells (Fig. 1C, arrowheads) but some U937 cells displayed budding into intracellular compartments (Fig. 1C, arrows). Immunoelectric microscopy indicated similar results (Fig. $1 \mathrm{C}$, most right panels). For quantification, we counted the number of cells containing particles at the PM alone or that of cells containing particles at both intracellular vesicles and the PM (Fig. 1D). Budding at the PM was prominent, regardless of whether cells were acutely or latently infected, or T lymphocytic or monocytic, suggesting that unlike chronically infected cells [10], HIV particles are most likely budded from the PM in latently infected cells, although it cannot be ruled out in this experiment that the particles observed in extracellular spaces might be released by exocytosis.

Gene expression analysis based on cDNA microarrays has extensively been employed and has provided evidence for the modulation of host cellular gene expression upon HIV infection (replication and latency) [15-20]. Although numerous host genes are modulated upon HIV infection, it is conceivable that expression levels of host membrane components may change by feedback regulation upon HIV reactivation, as HIV requires host cell membrane for particle budding. A membrane contains a number of microdomains, enriched in cholesterol (i.e., rafts) and in tetraspanins (e.g., CD63 and CD81), which accumulate at sites of HIV budding [7,21-26]. It has been shown that TSG101, a component of endosomal sorting complex required for transport (ESCRT) is recruited to the sites of particle assembly and is responsible for HIV particle budding $[27,28]$. Thus we chose endosomal (EEA1, CD63, HRS, TSG101, and Syntaxin12) and PM (CD44 and SNAP23) markers and quantified their mRNA levels by qRT-PCR (Fig. 2A and 2B) using the primer sets shown in Additional File 1 . Their properties and functions are as follows: EEA1 is a marker molecule for early endosome; HRS is an initial molecule for the ESCRT pathway; Syntaxin 12 is a SNARE molecule for endosomal membrane fusion; CD44 is an adhesion molecule implicated in cell migration; SNAP23 is a SNARE molecule for PM fusion in the exocytic pathway. When the mRNA levels in J1.1 cells stimulated with TNF- $\alpha$ were compared with those in unstimulated J1.1 cells, CD44 gene expression was increased, but the other genes tested were largely unaltered. No significant upregulation of CD44 was observed when cells of its uninfected parental line, Jurkat, were similarly stimulated with TNF- $\alpha$, indicating that the CD44 upregulation was not simply due to cell stimulation (Fig. 2A, upper). CD44 has been reported hardly expressed even at mRNA level in unstimulated Jurkat cells [29]. A similar analysis was carried out for U1 cells. Downregulation of CD44 has been reported for chronically infected monocytic cells [30]. Upon reactivation, CD44 upregulation was apparent but the endocytic molecules (CD63 

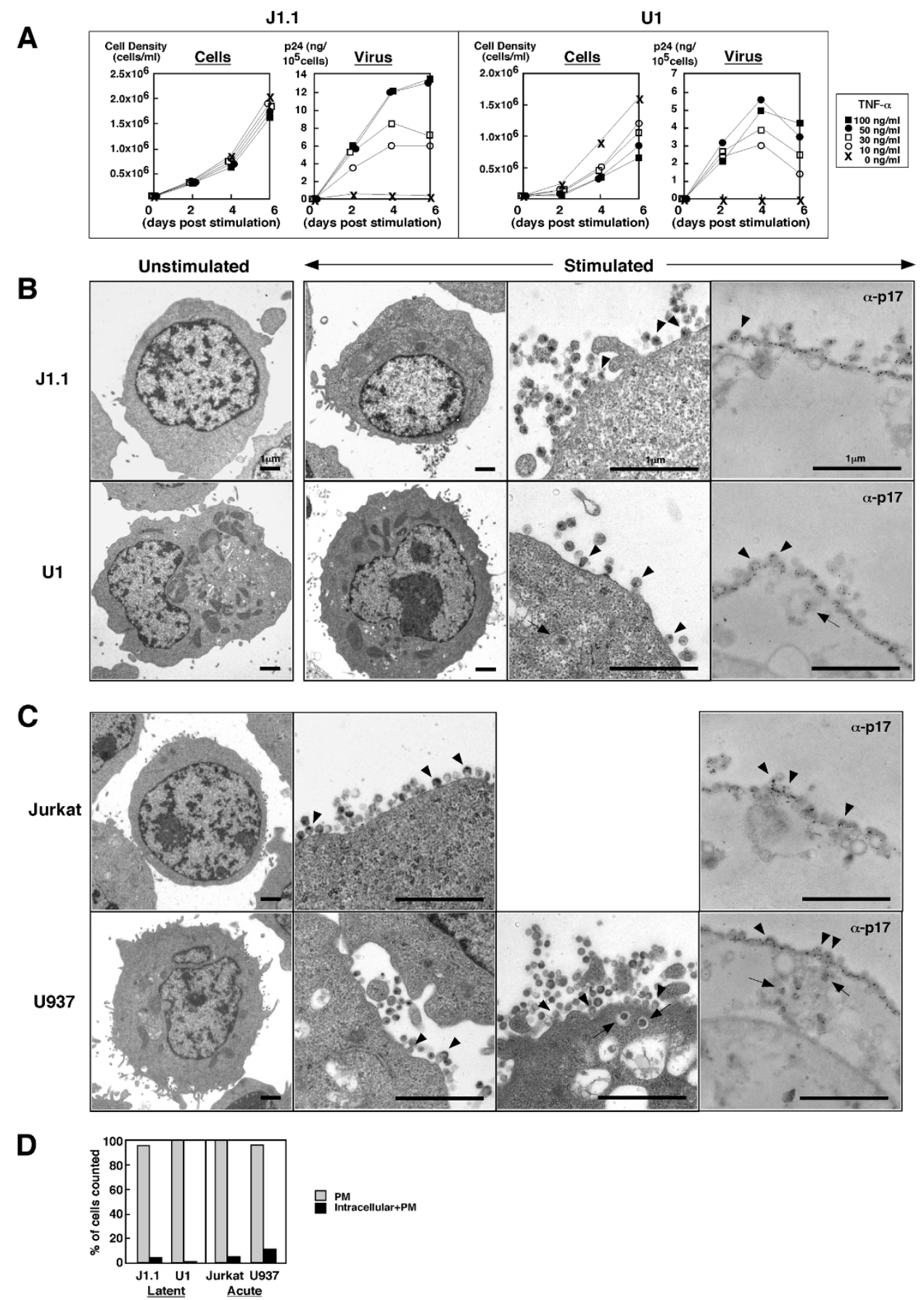

Figure I

Reactivation of latently infected JI.I and UI cells displays HIV particle budding at the PM. (A) HIV production from JI.I and UI cells upon TNF- $\alpha$ stimulation. JI.I and UI cells were stimulated with TNF- $\alpha(\sim 100 \mathrm{ng} / \mathrm{ml})$. Levels of particle production were measured by P24 antigen ELISA. (B) HIV particle budding from JI.I and UI cells upon TNF- $\alpha$ stimulation. JI.I and UI cells stimulated with $50 \mathrm{ng} / \mathrm{ml} \mathrm{TNF-} \alpha$ were subjected to conventional electron microscopy and immunoelectric microscopy using anti-HIV-I pI7MA antibody. (C) HIV particle budding from acutely infected Jurkat and U937 cells. Jurkat and U937 cells were infected with HIV-I (LAV strain) corresponding to 100-200 ng of p24CA antigen and were analyzed by electron microscopy. Arrowheads indicate budding particles and arrows indicate particles into intracellular vesicles in (B) and (C). (D) Semi-quantification of HIV-I particle localization. Approximately 300 of particle-positive cells observed by conventional electron microscopy were sorted into the categories indicated. 

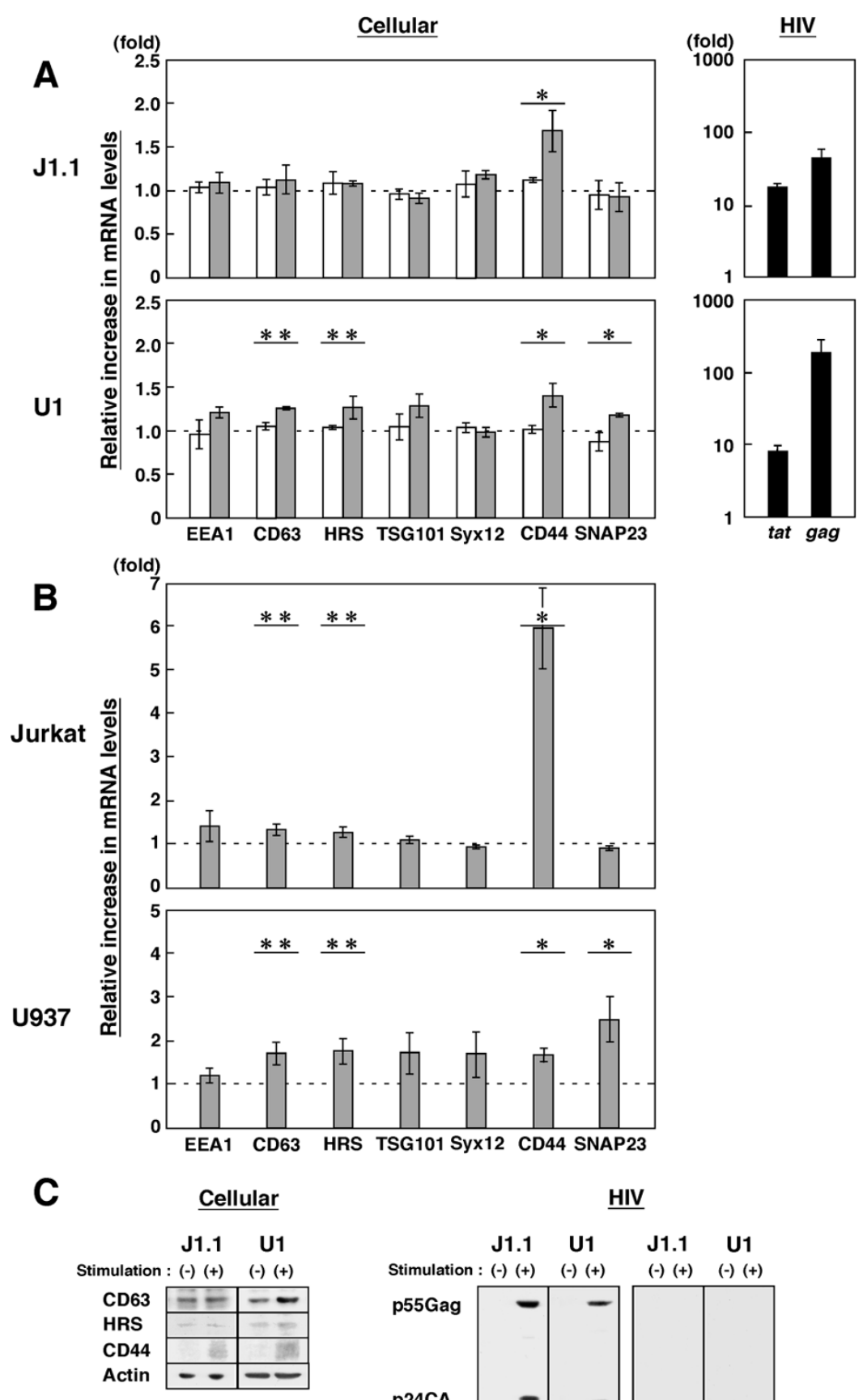

Figure 2 (see legend on next page)

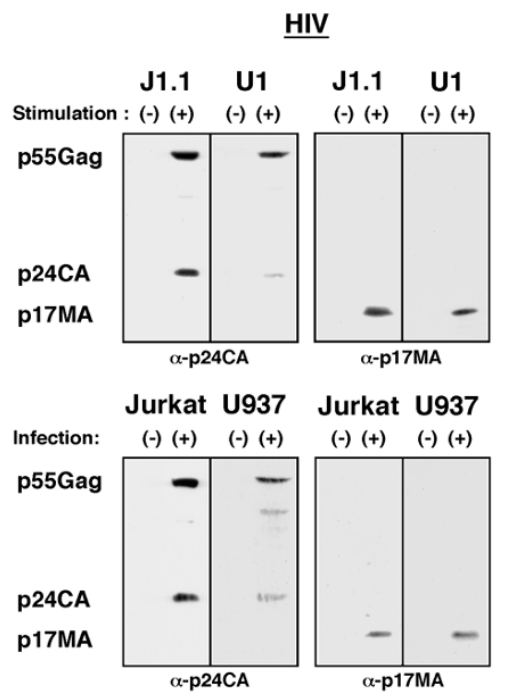


Figure 2 (see previous page)

HIV particle production is accompanied by mRNA upregulation of CD44 and endocytic molecules. (A) Differential gene expression upon reactivation. JI.I and UI cells were either unstimulated or stimulated with $50 \mathrm{ng} / \mathrm{ml}$ TNF- $\alpha$ (gray columns). For comparison, uninfected Jurkat and U937 cells were similarly stimulated (white columns). Expression of each gene was quantified by qRT-PCR and normalized to the level of GAPDH. The fold increase of expression of each gene upon stimulation was shown. *, $\mathrm{p}<0.01$; **, $\mathrm{p}<0.05$. Expression levels of HIV-I gag and tat mRNAs were quantified using specific primers (HIV-I nucleotide positions 70I-720 and 787-806 for gag and 5965-5987 and 8389-84 I for tat, respectively) (black columns). (B) Differential gene expression upon acute infection. Jurkat and U937 cells were infected with HIV-I and subjected to qRT-PCR. The fold increase of each gene expression upon infection was shown (gray columns). *, $p<0.01 ; * *, p<0.05$. (C) Protein expression of JI.I, UI, Jurkat, and U937 cells. TNF- $\alpha$ stimulation and infection were similarly performed. Cells were subjected to Western blotting using anti-CD44, anti-CD63, anti-HRS, anti-actin, anti-HIV-I pI7MA, and anti-p24CA antibodies.

and HRS) and SNAP23 were also upregulated in U1 cells. The modulation of others such as TSG101 was not statistically significant. These upregulations were not observed when uninfected U937 cells were stimulated (Fig. 2A, lower). The gene expression profiles upon reactivation were consistent with protein expression levels of the molecules when analyzed by Western blotting (Fig. 2C). We cannot simply compare the data of J1.1 and U1 cells, since expression levels of individual genes differ between the cell lines, but these significant upregulations were not observed in their parental but uninfected cells, suggesting that the upregulations might be linked with HIV expression. To test this possibility, we quantified expression levels of the same genes in acutely infected Jurkat and U937 cells and compared them with the levels in uninfected Jurkat and U937 cells. Upregulation of CD44 was observed in acutely infected Jurkat cells (Fig. 2B, upper), and this magnitude fold of upregulation was likely due to a very low level of CD44 expression in uninfected Jurkat cells [29]. In acutely infected U937 cells, besides CD44 upregulation, upregulation of other genes (CD63, HRS, and SNAP23) was observed (Fig. 2B, lower). Together, the results indicate that the upregulation of host molecules observed here was likely to be linked with HIV production. Higher levels of gag mRNA than tat mRNA observed in this study were possibly because we analyzed at a late stage of HIV replication. Western blotting confirmed HIV antigens, p55Gag precursor and its processing products, p24CA and p17MA, appeared upon reactivation or infection and showed that unlike anti-p24CA antibody, antip17MA antibody used in this study (against the C-terminal region of $\mathrm{p} 17 \mathrm{MA}$ ) recognized the mature p17MA domain but not the unprocessed p55Gag (Fig. 2C).

Confocal microscopy revealed that the anti-p17MA antibody specifically detected mature $\mathrm{p} 17 \mathrm{MA}$ produced upon HIV protease-mediated Gag processing (Fig. 3A). Since Gag processing occurs concomitant with particle budding, the p17MA signal obtained with the antibody most likely represents the sites of particle budding [4,31]. No p17MA signal was seen on the day after infection, indicating that it was not derived from residual HIV (Fig. 3A). When J1.1 and $\mathrm{U} 1$ cells were reactivated, the p17MA antigens were observed at the cell periphery, likely at the PM, but no signals were seen in unstimulated cells (Fig. 3B). Similarly, the p17MA antigens were observed at the PM in acutely infected Jurkat and U937 cells (Fig. 3C). For quantification, we counted the numbers of cells based on p17MA distribution patterns ( $\mathrm{PM}$, intracellular+PM, or negative) and confirmed that HIV particles were preferentially formed at the PM (Fig. 3D), consistent with the data obtained by electron microscopy (Fig. 1D).

To understand the significance of the upregulation of host molecules observed here, we examined intracellular localization of the molecules by immunostaining. No CD44 staining was found in unstimulated J1.1 and U1 cells, consistent with previous reports indicating CD44 downregulation during latency $[30,32]$. Following reactivation, CD44 was visible and colocalized with the p17MA antigens at the PM. Similarly, CD63 and HRS stainings were rarely seen in unstimulated cells but became visible and colocalized with the 17MA signals, especially in U1 cells (Fig. 3B). These findings were very apparent in acutely infected cells (Fig. 3C): CD63 recruitment, as reported previously for acutely infected Jurkat $\mathrm{T}$ cells and macrophages $[7,25,33,34]$, and HRS and CD44 accumulations to the sites where mature particles were formed. Together, our data suggest that HIV expression may lead to the upregulation of certain host molecules that are recruited to the sites of particle assembly, possibly to coordinate particle production. Because CD44 is a cell adhesion molecule that mediates lymphocyte aggregation and homing $[35,36]$, it is conceivable that the CD44 recruitment to HIV assembly sites may lead to an efficient cell-to-cell transmission of HIV and infected cell migration to lymph nodes.

In conclusion, despite numerous literature on HIV budding to intracellular compartments especially in macrophages, our data indicate that upon reactivation from latent infection, HIV predominantly buds at the PM, a 


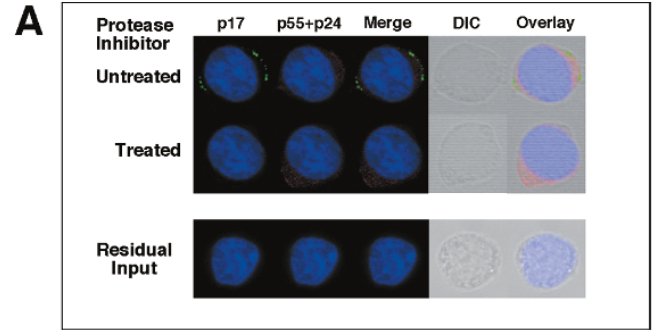

D

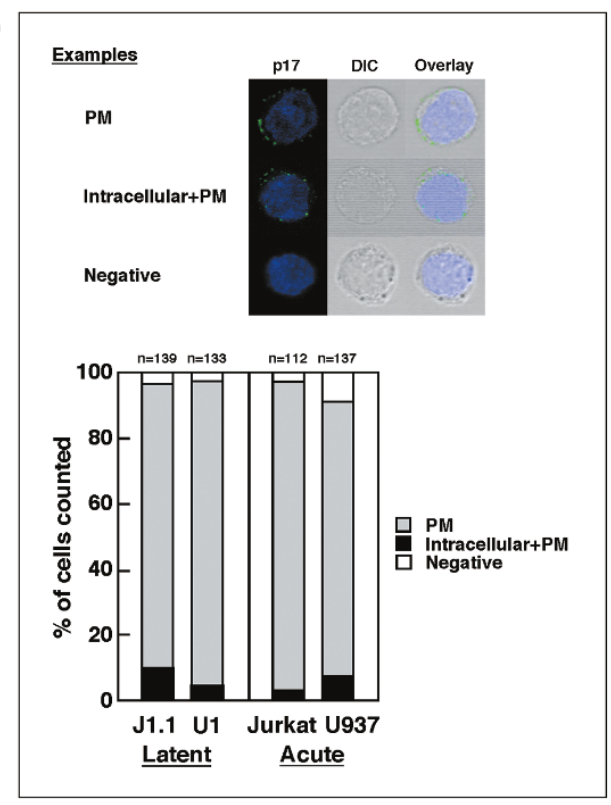

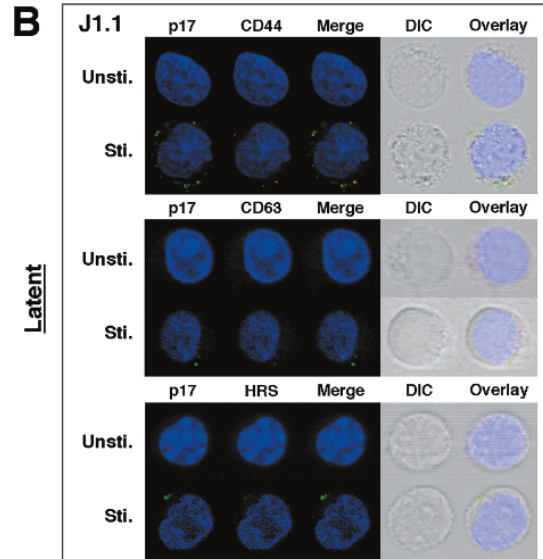

C

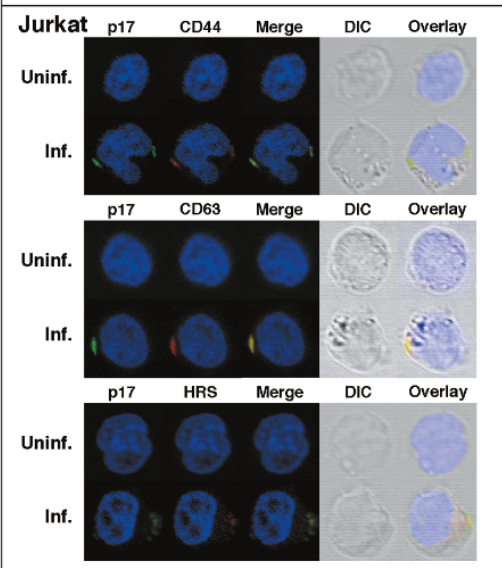

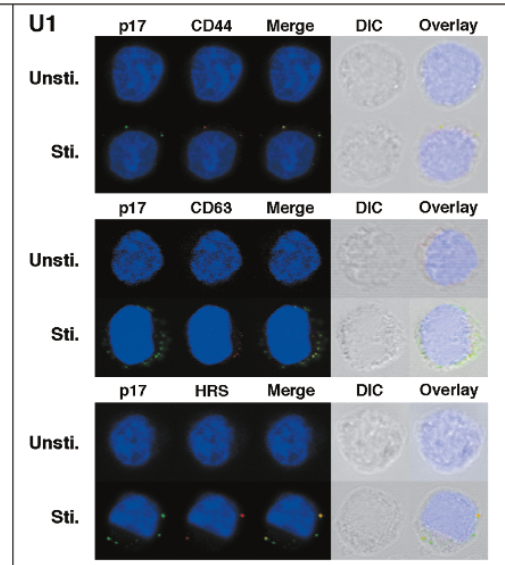
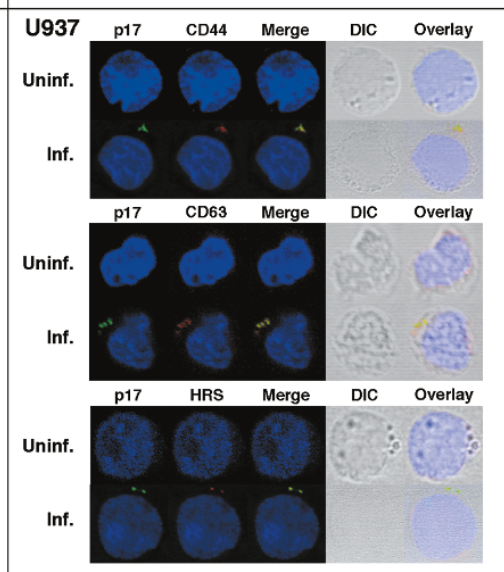

Figure 3

Upregulated molecules are accumulated to sites of HIV-I particle budding. (A) Inhibition of Gag processing in JI.I cells stimulated but treated with I $\mu \mathrm{M}$ ritonavir (upper) and residual HIV in Jurkat cells after infection (lower). For confocal microscopy, the cells were stained with anti-HIV-I pI7MA (green), p24CA (red) antibodies and with TOPRO-3 (blue). (B) Intracellular localization of upregulated molecules upon reactivation. JI.I and UI cells were either unstimulated (Unsti.) or stimulated (Sti.) with TNF- $\alpha$ and were immunostained with anti-p I7MA antibody (green) and antibodies for CD44, CD63, and HRS (red). (C) Intracellular localization of upregulated molecules upon acute infection. Jurkat and U937 cells were infected with HIV-I and immunostained. Inf., infected; Uninf., uninfected. (D) Semi-quantification of sites for HIV-I particle production. Examples of cells exhibiting PM staining alone, intracellular+PM accumulations, and no signals (negative) (upper). Based on PI7MA localization (PM, intracellular+PM, or negative), approximately 100-150 cells were sorted into the categories (lower).

morphology that is similar to particle budding in acute infection, suggesting that HIV latency have a potential for robust production of HIV observed for acute infection.

\section{Abbreviations}

HIV: human immunodeficiency virus; TNF- $\alpha$ : tumor necrosis factor- $\alpha$; CA: capsid; MA: matrix; qRT-PCR: quantitative RT-PCR; TSG101: tumor susceptibility gene-101; HRS: hepatocyte growth factor regulated tyrosine kinase substrate; EEA1: early endosomal antigen 1; SNAP23: synaptosome associated $23 \mathrm{kDa}$ protein.

\section{Competing interests}

The authors declare that they have no competing interests.

\section{Authors' contributions}

MS performed the qRT-PCR analysis and confocal study. $\mathrm{ED}, \mathrm{TG}$, and KS carried out the electron microscopy analysis. YM designed the experiment and wrote the manuscript. 


\section{Additional material}

\author{
Additional file 1 \\ Sequences of primer sets used in the study. \\ Click here for file \\ [http://www.biomedcentral.com/content/supplementary/1742- \\ 4690-6-63-S1.doc]
}

\section{Acknowledgements}

We thank M. Nakamura (Kitasato University, Japan) and Y. Fujioka (Osaka Medical College, Japan) for supporting electron microscopy analysis. This work was supported by an AIDS grant from the Ministry of Health, Labor, and Welfare of Japan and a grant from the Ministry of Sciences, Sports, and Education of Japan.

\section{References}

I. Amara A, Littman DR: After Hrs with HIV. J Cell Biol 2003, 162:37|-375.

2. Nguyen DG, Booth A, Gould SJ, Hildreth JE: Evidence that HIV budding in primary macrophages occurs through the exosome release pathway. I Biol Chem 2003, 278:52347-52354.

3. Nydegger S, Foti M, Derdowski A, Spearman P, Thali M: HIV-I egress is gated through late endosomal membranes. Traffic 2003, 4:902-910.

4. Ono A, Freed EO: Cell-type-dependent targeting of human immunodeficiency virus type I assembly to the plasma membrane and the multivesicular body. J Virol 2004, 78: $1552-1563$.

5. Pelchen-Matthews A, Kramer B, Marsh M: Infectious HIV-I assembles in late endosomes in primary macrophages. J Cell Biol 2003, 1 62:443-455.

6. Raposo G, Moore M, Innes D, Leijendekker R, Leigh-Brown A, Benaroch $P$, Geuze H: Human macrophages accumulate HIV-I particles in MHC II compartments. Traffic 2002, 3:718-729.

7. Deneka M, Pelchen-Matthews A, Byland R, Ruiz-Mateos E, Marsh M: In macrophages, HIV-I assembles into an intracellular plasma membrane domain containing the tetraspanins CD8I, CD9, and CD53. J Cell Biol 2007, I 77:329-34I.

8. Jouvenet $N$, Neil SJ, Bess C, Johnson MC, Virgen CA, Simon SM, Bieniasz PD: Plasma membrane is the site of productive HIVI particle assembly. PLoS Biol 2006, 4:e435.

9. Welsch S, Keppler OT, Habermann A, Allespach I, Krijnse-Locker J, Krausslich HG: HIV-I buds predominantly at the plasma membrane of primary human macrophages. PLOS Pathog 2007, 3:e36.

10. Pautrat G, Suzan M, Salaun D, Corbeau P, Allasia C, Morel G, Filippi $P$ : Human immunodeficiency virus type I infection of U937 cells promotes cell differentiation and a new pathway of viral assembly. Virology. 1900, I 79(2):749-758.

II. Biswas P, Poli G, Kinter AL, Justement JS, Stanley SK, Maury WJ, Bressler P, Orenstein JM, Fauci AS: Interferon gamma induces the expression of human immunodeficiency virus in persistently infected promonocytic cells (UI) and redirects the production of virions to intracytoplasmic vacuoles in phorbol myristate acetate-differentiated UI cells. J Exp Med 1992, I 76:739-750.

12. Butera ST, Roberts BD, Lam L, Hodge T, Folks TM: Human immunodeficiency virus type I RNA expression by four chronically infected cell lines indicates multiple mechanisms of latency. J Virol 1994, 68:2726-2730.

13. Perez VL, Rowe T, Justement JS, Butera ST, June CH, Folks TM: An HIV-I-infected $T$ cell clone defective in IL-2 production and Ca2+ mobilization after CD3 stimulation. J Immunol I99I, | 47:3|45-3|48.

14. Folks TM, Justement J, Kinter A, Dinarello CA, Fauci AS: Cytokineinduced expression of HIV-I in a chronically infected promonocyte cell line. Science 1987, 238:800-802.
15. Geiss GK, Bumgarner RE, An MC, Agy MB, van't Wout AB, Hammersmark E, Carter VS, Upchurc D, Mullins JI, Katze MG: Largescale monitoring of host cell gene expression during HIV-I infection using cDNA microarrays. Virology. 2000, 266(I):8-16.

16. Giri MS, Nebozhyn M, Showe L, Montaner LJ: Microarray data on gene modulation by HIV-I in immune cells: 2000-2006. J Leukoc Biol 2006, 80: I03 I-I043.

17. Krishnan V, Zeichner SL: Host cell gene expression during human immunodeficiency virus type I latency and reactivation and effects of targeting genes that are differentially expressed in viral latency. J Virol 2004, 78:9458-9473.

18. Munier S, Delcroix-Genete D, Carthagena L, Gumez A, Hazan U: Characterization of two candidate genes, NCoA3 and IRF8, potentially involved in the control of HIV-I latency. Retrovirology 2005, 2:73.

19. van't Wout AB, Lehrman GK, Mikheeva SA, O'Keeffe GC, Katze MG, Bumgarner RE, Geiss GK, Mullins Jl: Cellular gene expression upon human immunodeficiency virus type I infection of CD4(+)-T-cell lines. J Virol 2003, 77: I392-I402

20. Wen W, Chen S, Cao Y, Zhu Y, Yamamoto Y: HIV-I infection initiates changes in the expression of a wide array of genes in U937 promonocytes and HUT78 T cells. Virus Res 2005, I 1 3:26-35.

21. Aloia RC, Tian H, Jensen FC: Lipid composition and fluidity of the human immunodeficiency virus envelope and host cell plasma membranes. Proc Natl Acad Sci USA 1993, 90:5।8I-5I 85.

22. Brugger B, Glass B, Haberkant P, Leibrecht I, Wieland FT, Krausslich HG: The HIV lipidome: a raft with an unusual composition. Proc Natl Acad Sci USA 2006, I 03:264 I-2646.

23. Nguyen $\mathrm{DH}$, Hildreth JE: Evidence for budding of human immunodeficiency virus type I selectively from glycolipid-enriched membrane lipid rafts. J Virol 2000, 74:3264-3272.

24. Ono A, Freed EO: Plasma membrane rafts play a critical role in HIV-I assembly and release. Proc Natl Acad Sci USA 200I, 98: I3925-13930.

25. Jolly C, Sattentau QJ: Human immunodeficiency virus type I assembly, budding, and cell-cell spread in $\mathbf{T}$ cells take place in tetraspanin-enriched plasma membrane domains. J Virol 2007, 8 I :7873-7884.

26. Nydegger S, Khurana S, Krementsov DN, Foti M, Thali M: Mapping of tetraspanin-enriched microdomains that can function as gateways for HIV-I. J Cell Biol 2006, I 73:795-807.

27. Garrus JE, von Schwedler UK, Pornillos OW, Morham SG, Zavitz KH, Wang HE, Wettstein DA, Stray KM, Cote M, Rich RL, Myszka DG, Sundquist WI: TsgIOI and the vacuolar protein sorting pathway are essential for HIV-I budding. Cell 200I, I 07:55-65.

28. Martin-Serrano J, Zang T, Bieniasz PD: HIV-I and Ebola virus encode small peptide motifs that recruit Tsg IOI to sites of particle assembly to facilitate egress. Nat Med 200I, 7:1313-1319.

29. Dukes CS, Yu Y, Rivadeneira ED, Sauls DL, Liao HX, Haynes BF, Weinberg JB: CD44S as a determinant of human immunodeficiency virus type I infection and cellular tropism. J Virol I995, 69:4000-4005.

30. Guo MM, Hildreth JE: HIV-induced loss of CD44 expression in monocytic cell lines. J Immunol 1993, I 5 I:2225-2236.

31. Ono A, Orenstein JM, Freed EO: Role of the Gag matrix domain in targeting human immunodeficiency virus type I assembly. J Virol 2000, 74:2855-2866.

32. Giordanengo V, Limouse M, Doglio A, Lesimple J, Lefebvre JC: Alteration of CD44 expression in HIV type I-infected $T$ cell lines. AIDS Res Hum Retroviruses 1996, I 2:1615-1622.

33. Booth AM, Fang Y, Fallon JK, Yang JM, Hildreth JE, Gould SJ: Exosomes and HIV Gag bud from endosome-like domains of the T cell plasma membrane. J Cell Biol 2006, I 72:923-935.

34. Ruiz-Mateos E, Pelchen-Matthews A, Deneka M, Marsh M: CD63 is not required for production of infectious human immunodeficiency virus type I in human macrophages. J Virol 2008, 82:475 I-476I.

35. Goodison S, Urquidi V, Tarin D: CD44 cell adhesion molecules. Mol Pathol 1999, 4:189-196.

36. Isacke CM: The role of the cytoplasmic domain in regulating CD44 function. J Cell Sci 1994, 107:2353-2359. 